\title{
Implementation of User Centered Design in User Experience Architecture for Geo-COVID mobile Applications
}

\author{
Devie Rosa Anamisa, Fifin Ayu Mufarroha* , Fauziah Reza Oktaviyani, Nanda Prabu Angganata, M. Dimas Arya \\ Muhajir \\ Faculty of Engineering, University of Trunojoyo Madura, 69162, Indonesia
}

\begin{abstract}
In Indonesia, there has been a significant increase in positive confirmed cases of Covid-19 caused by mutations in the Alpha, Beta and Delta variants. The uncontrolled spread has overwhelmed hospitals to treat Covid-19 patients. Hospitals are full of COVID-19 patients, making many people hesitate to check their health conditions. Geo-COVID is a one-stop application that aims to make it easier for the public to access health consultations, buy drugs online so as to reduce activities outside the home, PCR testing from home, transparency of information on the spread of COVID-19 cases, and sharing with families affected by COVID-19. The method used in the Geo-COVID architecture is User Centered Design. User Centered Design is a system design method that focuses on potential users. The stages used in achieving application goals in Geo-COVID design are Understanding the Context of Use, Determining User Needs, Design Solutions, Design Evaluation of User Needs. The target users of the Geo-COVID application are Indonesian people who are active outside the home and often interact with many individuals. The Geo-COVID application is oriented towards user experience which is limited to the Covid-19 distribution map in Indonesia, public health services, using a GUI interface type.
\end{abstract}

Keywords: User experience; Mobile application; COVID-19; User centere

\section{Introduction}

The pandemic indicates a rapid COVID-19 infection caused by the 2019 Novel Coronavirus or 2019-nCoV, so that many regions of the world have been infected [1]-[6]. In most cases, this virus causes only mild respiratory infections, such as the flu [7]-[15]. However, this virus can also cause severe respiratory infections, such as lung infections (pneumonia) [16]. This virus is transmitted through phlegm (droplets) from the respiratory tract, for example when in a crowded closed room with poor air circulation or direct contact with droplets. In Indonesia, the COVID-19 pandemic has not yet reached its final stage. After more than a year since the first case was confirmed and announced by the government, it was able to reduce positive confirmed cases and patients being treated. However, the trend of increasing positive cases in Indonesia has increased again.

The increasingly uncontrolled spread of cases has made many hospitals overwhelmed in handling patients [17]-[20]. So, for now, many hospitals are prioritized to treat patients who are confirmed positive for COVID19. With the situation in the hospital being tense, people are afraid to have their health checked. This has made many victims of COVID-19 unsaved because of the tendency of people who wait for severe conditions to first check their conditions to the hospital. The increasingly uncontrolled spread of cases has forced the government to re-implement policies that were previously relaxed. In addition, this has an impact on the community's economic space in meeting the needs of life which has a major impact on the economic resilience of the family.

As a result, many communities are in need of assistance to restore their economic conditions. Based on the problems described above, an application "GeoCOVID" is presented to be a solution so that people can consult about health problems with experts and also take advantage of technological developments. Geo-COVID is a one-stop application based on Android and IoS which is the answer to the above problems. Where users can not only consult but can also test PCR independently to patients who have symptoms at their respective homes, find and buy drugs, view maps of the distribution of confirmed cases to provide assistance to those in need.

\section{Methodology}

User Centered Design is a system design method that focuses on potential users. To ensure that the product will create the best user experience, designers involve

\footnotetext{
*Corresponding author : fifin.mufarroha@trunojoyo.ac.id
} 
users throughout the design process. This includes considering the goals, requirements, and user feedback about the app. The following stages of the User Centered Design method used in achieving the objectives of the developed application are shown in Figure 1.

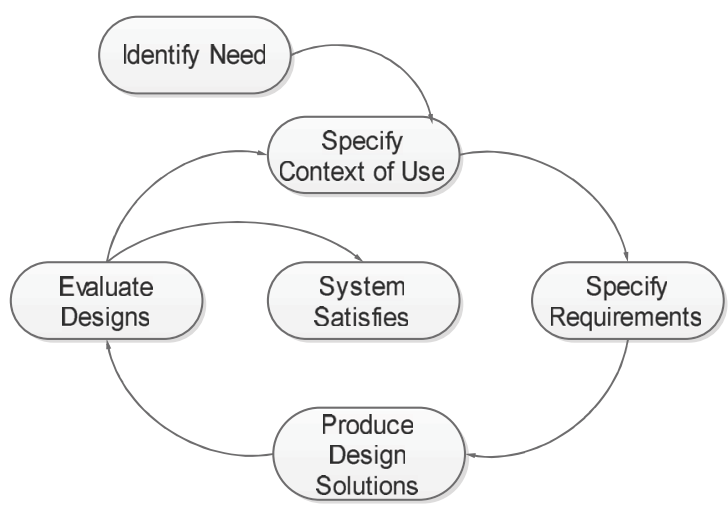

Fig. 1 User centered design

\subsection{Understanding Usage Context}

To find out user needs, direct interaction with potential users is carried out through interviews and surveys. As a result, the characteristics, cognition, and attitudes of users are understood. From here, you can find out the use cases of the application and start designing.

\subsection{Determining User Needs}

User requirements include user interfaces, help systems, technical support, to initial installation and configuration procedures. After collecting data by means of interviews or surveys, a collection of information about users is obtained such as background, needs, problems, and what users want. As a result, the information is analyzed to determine user needs.

\subsection{Design Solution}

This stage involves generating ideas, testing, and refining solutions based on user input requirements. While working at this stage, it is important to keep users engaged so that the application can be continuously modified to meet their needs. As user needs change over time, it's important to keep testing ideas to make sure the solutions you get are still relevant. This phase will continue until the designer and user are satisfied with the result.

\subsection{Design Evaluation}

At this stage, testing the system or seeking feedback from potential users on the design that has been made. This stage provides insight into how users will interact with the application interface and understands how to customize it to better suit users.

\section{Results and Discussion}

This session discusses how the methods described in the previous chapter are applied. In user experience design, user centered design is chosen as the design methodology.

\subsection{Target User}

In making this user experience design, the Indonesian people, especially those who often do activities outside the home, we consider to be potential targets because they often interact with several individuals who are not known to have symptoms or the individual is in good health..

\subsubsection{Demografis}

During this Covid-19 pandemic, demographic aspects are needed such as age, family structure, residential patterns and individual characteristics in socializing, which is very clearly visible is the age factor to determine morbidity (illness) and mortality (death) in this COVID-19 case. .

\subsubsection{Geografis}

If we look at the spread of covid contained on the covid19.go.id page, it can be seen that there are more than 30 provinces that have been exposed to this virus, and it is possible that other provinces are also exposed..

\subsubsection{Psikologis}

Seeing the Indonesian people every day only some of the behavior that cares about this pandemic, not many people are very obedient to government policies to break the chain of distribution, currently Covid in Indonesia is even increasing. And this increase in cases makes the Indonesian people even more afraid of tests, vaccines, and so on. There are even those who have tested positive but are not self-isolating

\subsubsection{Behavioral}

People who understand technology in this case can access using the internet and have devices that can be connected. Mobile applications have become an application that every individual uses every day, so the use of applications is familiar to them.

\subsection{Implementasi dan Desain Solusi}

The implementation and design stages of this solution are carried out using a Wifeframe. Wireframe is a tool that is used as a basic form of design solution design. Figure 2 shows the initial view when the user opens the application. Several splash screens will appear which 
ends on the system wanting the user to login. Authenticated users will be redirected to the home page by displaying patient condition information, outbreak distribution maps, consultation features, and pharmacy features.

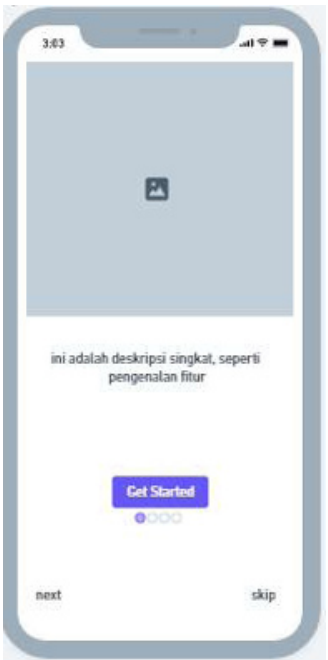

(a)

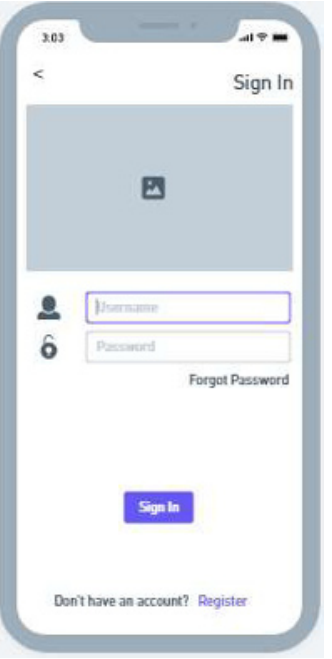

(b)
Fig. 2. Initial screen, (a) Splash Screen (b)Login

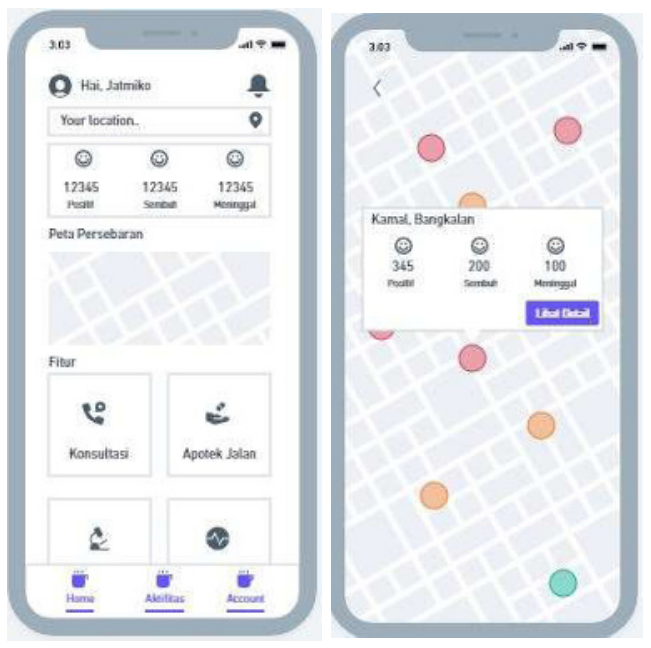

Fig. 3. Home page

The Consultation feature serves to make it easier for users to conduct questions and answers with experts about their conditions or symptoms. The consultation is carried out by conducting a question and answer session with the doctor with a general appearance such as a message display. The details of this feature are shown in Figure 4. Meanwhile, the pharmacy feature is used by users to buy medicines. This feature allows users to be able to make drug purchases without having to go to a pharmacy. The user can choose the drug according to the symptoms and all transactions are carried out through the system. The system will display a list of drugs purchased along with the amount and total payment.

In addition to these two features in this application, a feature is also added to help users carry out a covid test. This feature is proposed considering that the available tests make the user have to come to the hospital or the test location so that when using the feature later the user can choose the type of test and also

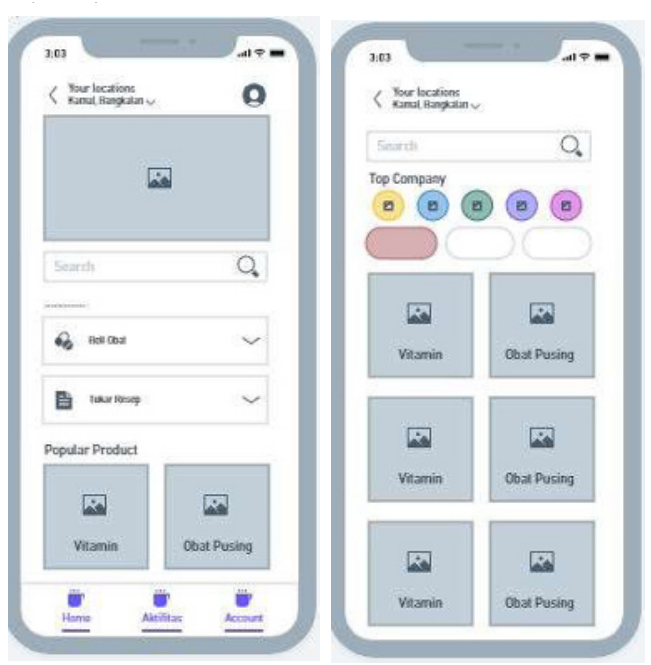

Fig. 4. Pharmacy Features

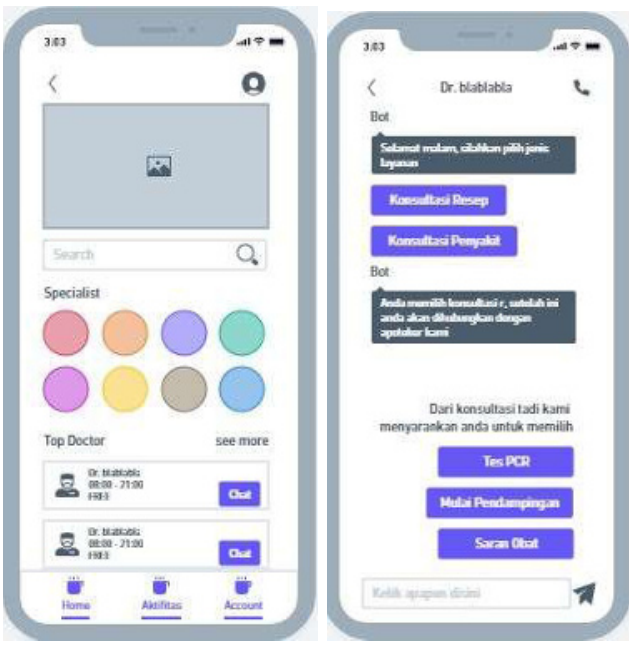

Fig. 5. Consultation Features

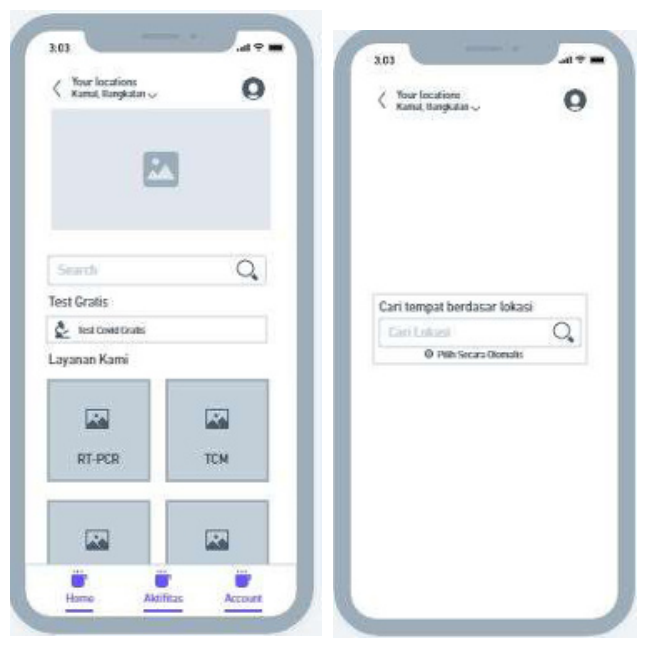

Fig. 6. Covid Test Features 


\section{Conclusion}

The design of user experience in this study answers the existing problems by finding user needs from demographic, geographical, psychological, and behavioral aspects. Based on data from the target user, the features needed in the design include a map of the spread of COVID, the number of patients, consultations, pharmacies, and covid tests. From the features obtained, a solution design design is made in the form of a wireframe. The objectives of designing the Geo-COVID application include (1) public health services are still guaranteed even in the middle, social restrictions due to the Covid-19 pandemic, (2) reduce activities outside the home because they can buy drugs online, (3) increase the number of tracing and testing because the community no longer need to worry about doing PCR tests independently without crowding, (4) Ease of getting information on the spread of covid cases in real time so that people can be alert if in the area where they live there is a significant increase in cases For further research, the author will carry out feature development and also conduct a more detailed analysis of the target user.

\section{References}

[1] T. D. Pham, L. Dwyer, J.-J. Su, and T. Ngo, "COVID-19 impacts of inbound tourism on Australian economy," Ann. Tour. Res., vol. 88, p. 103179, (2021), doi: https://doi.org/10.1016/j.annals.2021.103179.

[2] E. Razumovskaia, L. Yuzvovich, E. Kniazeva, M. Klimenko, and V. Shelyakin, "The Effectiveness of Russian Government Policy to Support SMEs in the COVID-19 Pandemic," Journal of Open Innovation: Technology, Market, and Complexity, vol. 6, no. 4. (2020), doi: 10.3390/joitmc6040160.

[3] S. E. Obi, T. Yunusa, A. N. Ezeogueri-Oyewole, S. S. Sekpe, E. Egwemi, and A. S. Isiaka, "The Socio-Economic Impact of Covid-19 on The Economic Activities of Selected States in Nigeria ," Indones. J. Soc. Environ. Issues, vol. 1, no. 2 SE-, pp. 39-47, Aug. (2020), doi: 10.47540/ijsei.v1i2.10.

[4] T. Hale et al., "A global panel database of pandemic policies (Oxford COVID-19 Government Response Tracker)," Nat. Hum. Behav., vol. 5, no. 4, pp. 529-538, (2021), doi: 10.1038/s41562-021-01079-8.

[5] A. Altiparmakis, A. Bojar, S. Brouard, M. Foucault, H. Kriesi, and R. Nadeau, "Pandemic politics: policy evaluations of government responses to COVID-19," West Eur. Polit., vol. 44, no. 5-6, pp. 1159-1179, Sep. (2021), doi: 10.1080/01402382.2021.1930754.

[6] F. C. Permana, Z. M. Wicaksono, C.
Kurniawan, A. S. Abdullah, and B. N. Ruchjana, "Perception analysis of the Indonesian society on twitter social media on the increase in BPJS kesehatan contribution in the Covid 19 pandemic era," J. Phys. Conf. Ser., vol. 1722, p. 12022, (2021), doi: 10.1088/17426596/1722/1/012022.

[7] J. R. Larsen, M. R. Martin, J. D. Martin, P. Kuhn, and J. B. Hicks, "Modeling the Onset of Symptoms of COVID-19," Frontiers in Public Health , vol. 8. p. 473, (2020), [Online]. Available:

https://www.frontiersin.org/article/10.3389/fpu bh.2020.00473.

[8] X. Song, M. Delaney, R. K. Shah, J. M. Campos, D. L. Wessel, and R. L. DeBiasi, "Comparison of Clinical Features of COVID-19 vs Seasonal Influenza A and B in US Children," JAMA Netw. Open, vol. 3, no. 9, pp. e2020495e2020495, Sep. (2020), doi: 10.1001/jamanetworkopen.2020.20495.

[9] J. Czubak, K. Stolarczyk, A. Orzeł, M. Frączek, and T. Zatoński, "Comparison of the clinical differences between COVID-19, SARS, influenza, and the common cold: A systematic literature review," Adv. Clin. Exp. Med., vol. 30, no. 1, pp. 109-114, (2021), doi: 10.17219/acem/129573.

[10] M. Honigsbaum and L. Krishnan, "Taking pandemic sequelae seriously: from the Russian influenza to COVID-19 long-haulers," Lancet, vol. 396, no. 10260, pp. 1389-1391, Oct. (2020), doi: 10.1016/S0140-6736(20)32134-6.

[11] W. B. Grant, C. A. Baggerly, and H. Lahore, "Reply: 'Vitamin D Supplementation in Influenza and COVID-19 Infections. Comment on: Evidence That Vitamin D Supplementation Could Reduce Risk of Influenza and COVID-19 Infections and Deaths Nutrients 2020, 12(4), 988,"” Nutrients , vol. 12, no. 6. (2020), doi: 10.3390/nu12061620.

[12] A. Pormohammad et al., "Comparison of influenza type A and B with COVID-19: A global systematic review and meta-analysis on clinical, laboratory and radiographic findings," Rev. Med. Virol., vol. 31, no. 3, p. e2179, May (2021), doi: https://doi.org/10.1002/rmv.2179.

[13] C. H. Yan, F. Faraji, D. P. Prajapati, C. E. Boone, and A. S. DeConde, "Association of chemosensory dysfunction and COVID-19 in patients presenting with influenza-like symptoms," Int. Forum Allergy Rhinol., vol. 10, no. 7, pp. 806-813, Jul. (2020), doi: https://doi.org/10.1002/alr.22579.

[14] S. A. Hashemi et al., "Co-infection with COVID-19 and influenza A virus in two died patients with acute respiratory syndrome, Bojnurd, Iran," J. Med. Virol., vol. 92, no. 11, pp. 2319-2321, Nov. (2020), doi: 
10.1002/jmv.26014.

[15] S. Zayet et al., "Clinical features of COVID-19 and influenza: a comparative study on Nord Franche-Comte cluster," Microbes Infect., vol. 22, no. 9, pp. 481-488, (2020), doi: https://doi.org/10.1016/j.micinf.2020.05.016.

[16] M. Liu, W. Zeng, Y. Wen, Y. Zheng, F. Lv, and K. Xiao, "COVID-19 pneumonia: CT findings of 122 patients and differentiation from influenza pneumonia," Eur. Radiol., vol. 30, no. 10 , pp. 5463-5469, (2020), doi: 10.1007/s00330-020-06928-0.

[17] A. Guillon, E. Laurent, L. Godillon, A. Kimmoun, and L. Grammatico-Guillon, "Interregional transfers for pandemic surges were associated with reduced mortality rates," Intensive Care Med., vol. 47, no. 7, pp. 798800, (2021), doi: 10.1007/s00134-021-06412-3.

[18] A. J. Holmgren, N. C. Apathy, and J. AdlerMilstein, "Barriers to hospital electronic public health reporting and implications for the COVID-19 pandemic," J. Am. Med. Informatics Assoc., vol. 27, no. 8, pp. 1306-1309, Aug. (2020), doi: 10.1093/jamia/ocaa112.

[19] J. Bodilsen et al., "Hospital admission and mortality rates for non-covid diseases in Denmark during covid-19 pandemic: nationwide population based cohort study," $B M J$, vol. 373, p. n1135, May (2021), doi: 10.1136/bmj.n1135.

[20] P. Ayoub et al., "Medical Student Mobilization During a Pandemic: The Ochsner Clinical School Response to COVID-19," Ochsner J., vol. 20, no. 2, pp. 146 LP - 150, Jun. (2020), doi: $10.31486 /$ toj.20.0069. 